Supplement of

\title{
Parameterization retrieval of trace gas volume mixing ratios from Airborne MAX-DOAS
}

Barbara Dix et al.

Correspondence to: Rainer Volkamer (rainer.volkamer@colorado.edu)

The copyright of individual parts of the supplement might differ from the CC-BY 3.0 licence. 
Table S1 Box-AMF interpolation fit parameter

\begin{tabular}{lccc}
\hline Parameter & slope & intercept & $\mathbf{R}^{\mathbf{2}}$ \\
\hline Box-AMF & & & \\
$360 \mathrm{~nm}$ to $350 \mathrm{~nm}$ & $0.9997 \pm 0.0001$ & $0.001 \pm 0.001$ & 0.9997 \\
$477 \mathrm{~nm}$ to $447 \mathrm{~nm}$ & $0.9997 \pm 0.0001$ & $0.001 \pm 0.002$ & 0.9997 \\
$477 \mathrm{~nm}$ to $428 \mathrm{~nm}$ & $0.9992 \pm 0.0002$ & $0.003 \pm 0.002$ & 0.9992 \\
\hline
\end{tabular}



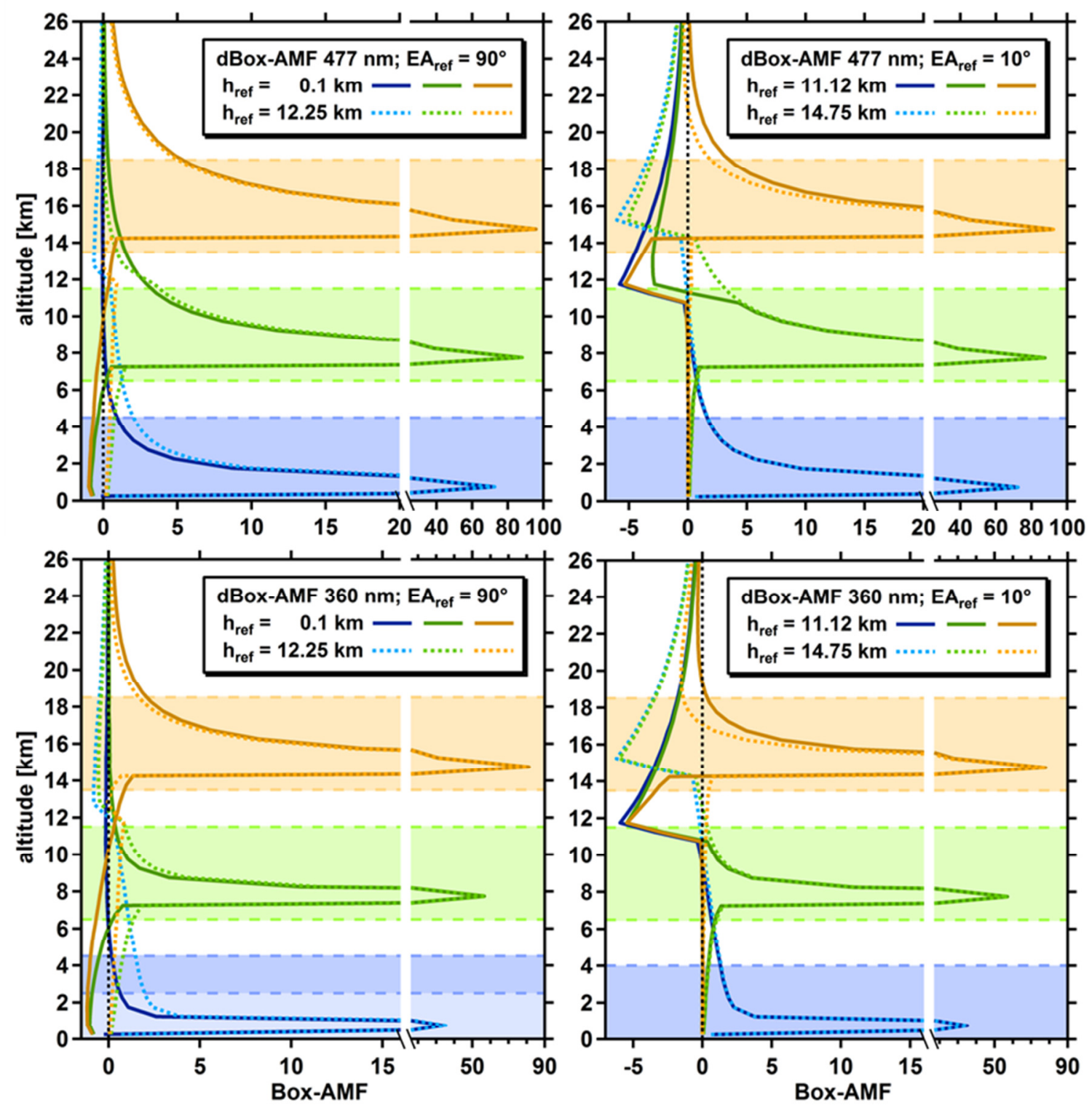

Figure S1 DBox-AMF traces at $477 \mathrm{~nm}$ (top) and $360 \mathrm{~nm}$ (bottom) nm for $0.75 \mathrm{~km}, 7.75 \mathrm{~km}$ and $14.75 \mathrm{~km}$ aircraft altitude and different references, calculated at solar zenith angle of $10^{\circ}$. Respective sensitive ranges are indicated by color shadings. Note that at $360 \mathrm{~nm}$ and $0.75 \mathrm{~km}$, the upper boundary layer is at $1.5 \mathrm{~km}$ above aircraft altitude when using an EA $90^{\circ}$ reference with a reference height, $h_{r e f}$, of $12.25 \mathrm{~km}$, and $3 \mathrm{~km}$ above for an EA $10^{\circ}$ reference. Both $n_{U}$ layers are below the $3.5 \mathrm{~km}$ limit. The more flexible upper limit accounts for different dBox-AMF peak shapes that depend on wavelength, altitude and choice of reference. 


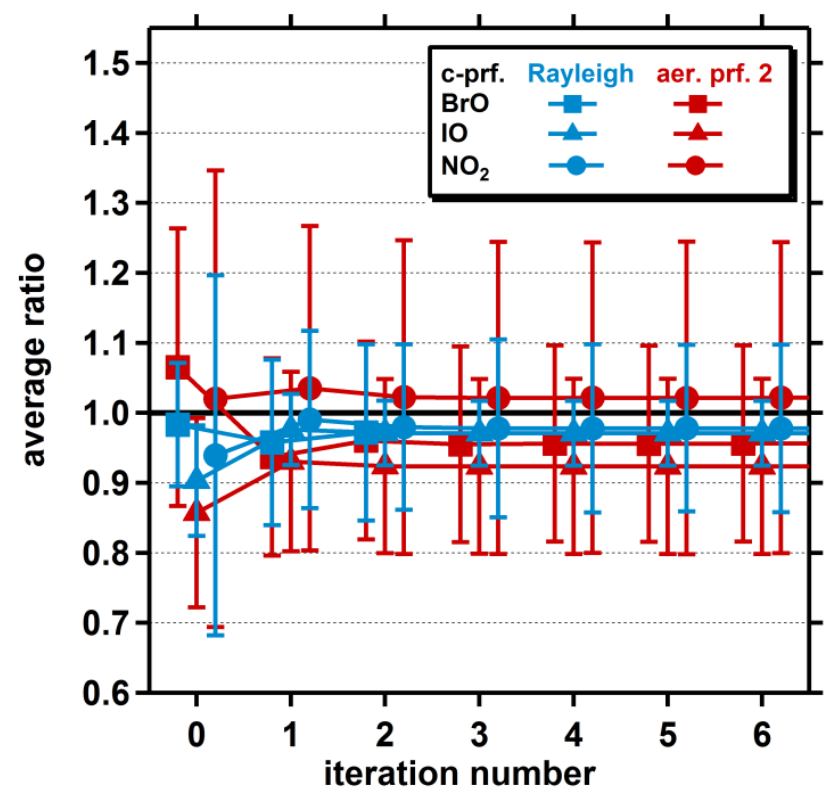

Figure S2 Ratios of retrieved and real VMR averaged over all altitudes for $\mathrm{BrO}, \mathrm{IO}$ and $\mathrm{NO}_{2}$ c-profiles for Rayleigh and aerosol 2 case studies plotted over iteration number. Averages for different trace gases are offset for better visibility. Error bars are one standard deviation. The most significant change is observed between $i=0$ and $i=1$, due to $\mathrm{dSCD}_{\text {trop }}^{\mathrm{i}} \neq 0$ after the initial iteration.

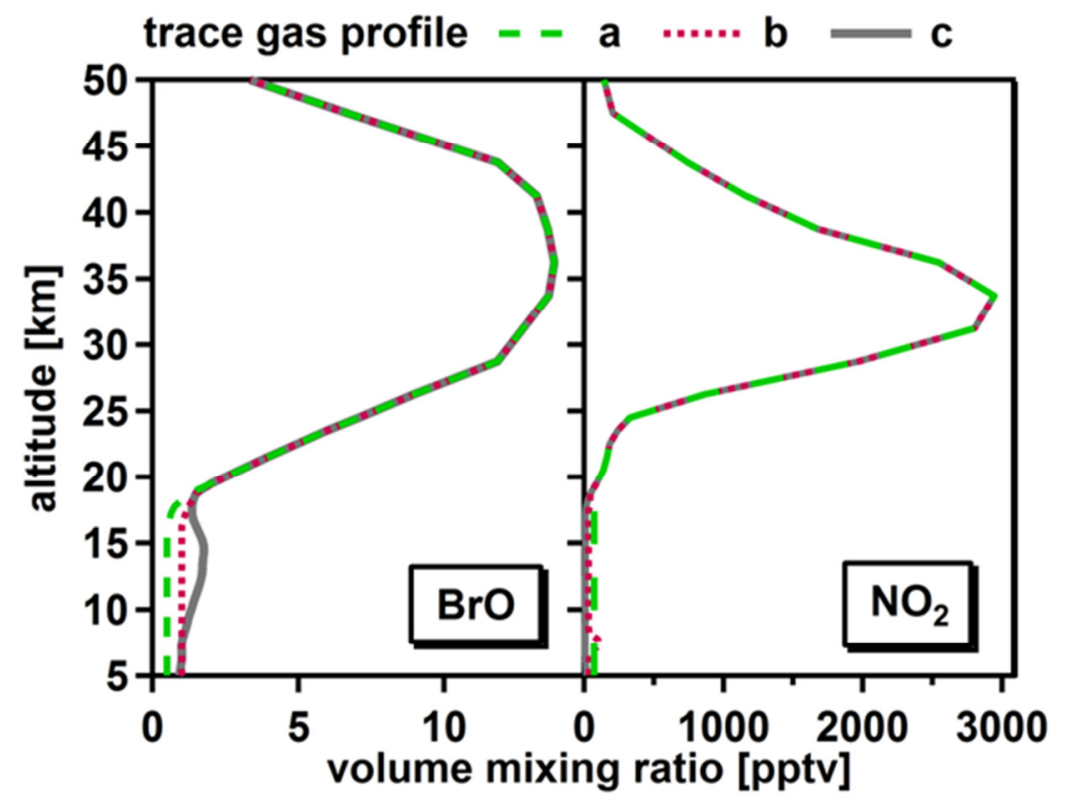

Figure S3 Stratospheric profiles for $\mathrm{BrO}$ and $\mathrm{NO}_{2}$ used for the simulation of dSCD data with $\mathrm{VCD}_{\text {strat }}=1.1 \mathrm{x}$ $10^{13}$ molec $\mathrm{cm}^{-2}$ and $1.3 \times 10^{15}$ molec $\mathrm{cm}^{-2}$ for $\mathrm{BrO}$ and $\mathrm{NO}_{2}$ respectively. 


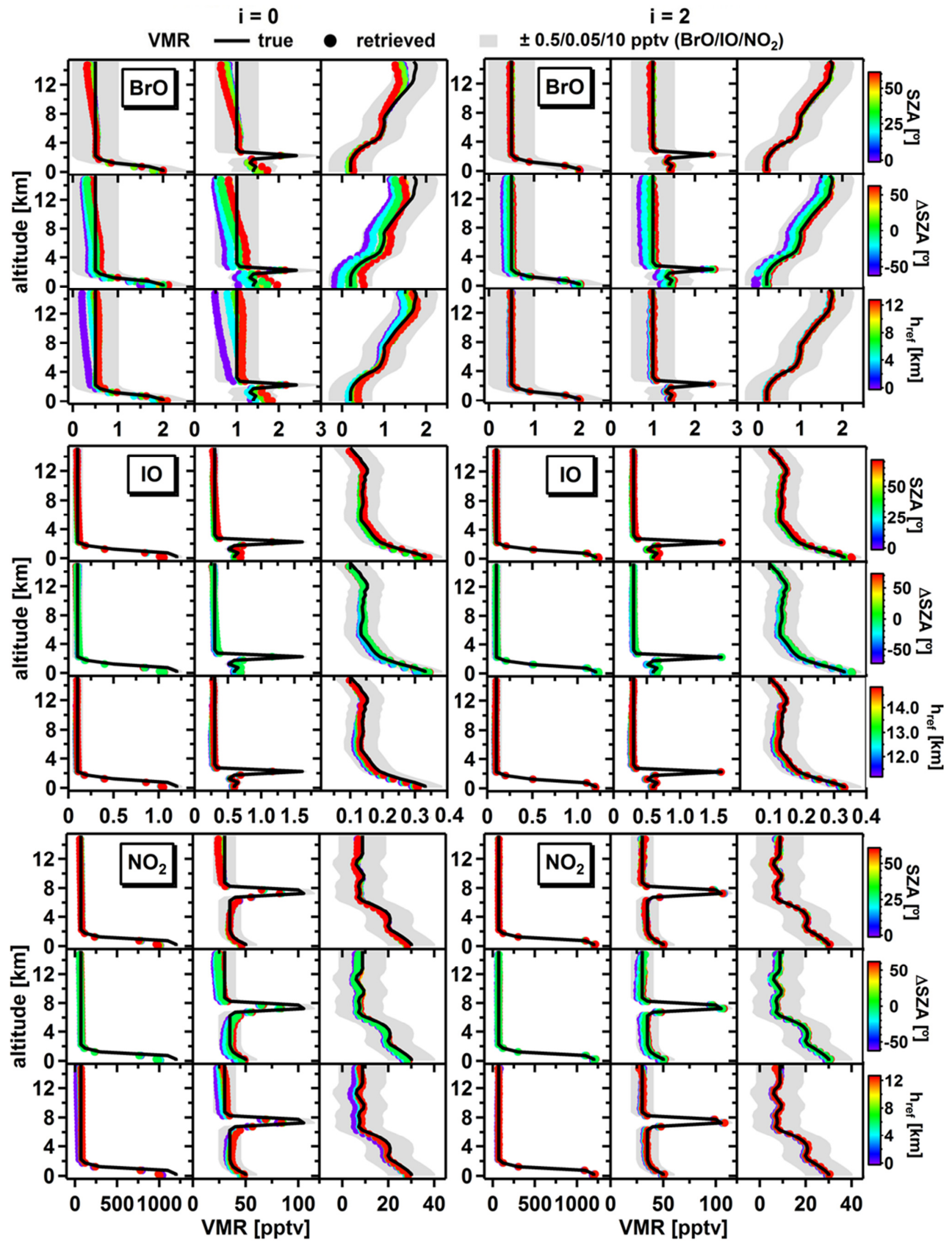


Figure S4. $\mathrm{VMR}_{\text {para }}$ for $\mathrm{BrO}$ (top), $\mathrm{IO}$ (middle) and $\mathrm{NO}_{2}$ (bottom) a-, b-, and c-profiles using dSCD data simulated for a Rayleigh atmosphere for select cases. The left column shows results for $i=0$, while the right column displays the same data after the third iteration ( $i=2)$. Grey shading denotes \pm 0.5 pptv for BrO, \pm 0.05 pptv for $\mathrm{IO}$, and \pm 10 pptv for $\mathrm{NO}_{2}$. True trace gas profiles are included as reference. $\mathrm{VMR}_{\text {para }}$ are color coded by SZA, $\triangle \mathrm{SZA}$, and $h_{r e f}$. For changes in SZA and $\triangle \mathrm{SZA}$ the reference altitude was fixed at $4.25 \mathrm{~km}$ for $\mathrm{BrO}$ and $\mathrm{NO}_{2}$, and at $14.25 \mathrm{~km}$ for IO. For changes in SZA and $h_{r e f}, \Delta \mathrm{SZA}$ is $0^{\circ}$, and for changes in $h_{r e f} \mathrm{SZA}$ is set to $25^{\circ}$ and $\triangle \mathrm{SZA}$ is $0^{\circ}$. 

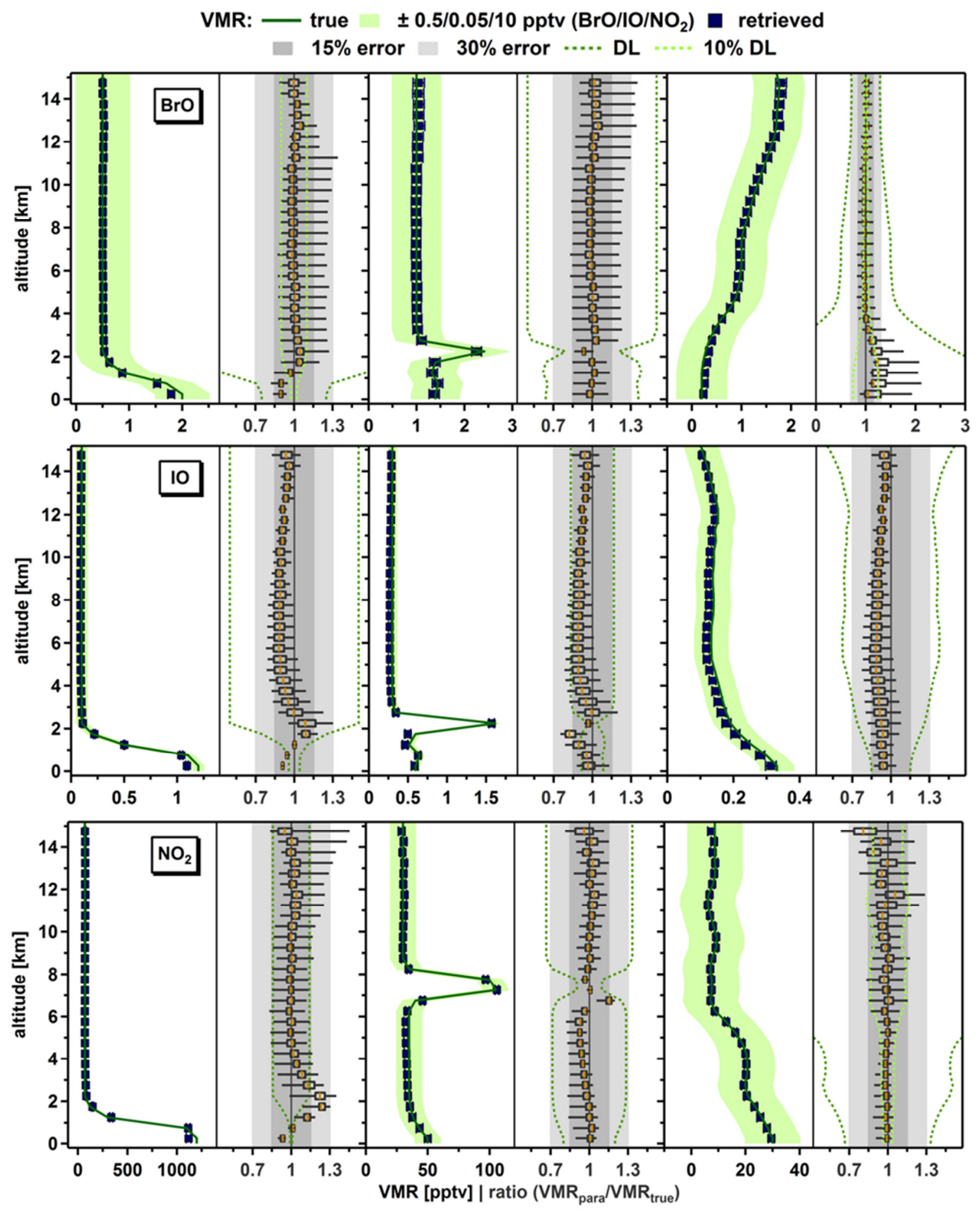

Figure S5. $\mathrm{VMR}_{\text {para }}$ for $\mathrm{BrO}$ (top), $\mathrm{IO}$ (middle) and $\mathrm{NO}_{2}$ (bottom) a-, b-, and c- profiles (left to right), using $\mathrm{dSCD}$ data simulated for aerosol 1. Individual left panels show $\mathrm{VMR}_{\text {para }}$ average and standard deviation. Original trace gas profiles are included as reference and green shading denotes individual trace gas VMR error bounds. Right panels display altitude resolved whisker plots of the ratios of $\mathrm{VMR}_{\text {para }}$ over $\mathrm{VMR}_{\text {true }}$, showing the median (orange) and 5, 25, 75 and 95 percentiles. Grey shaded areas indicate $15 \%$ and $30 \%$ error; green dashed lines show trace gas detection limits. 

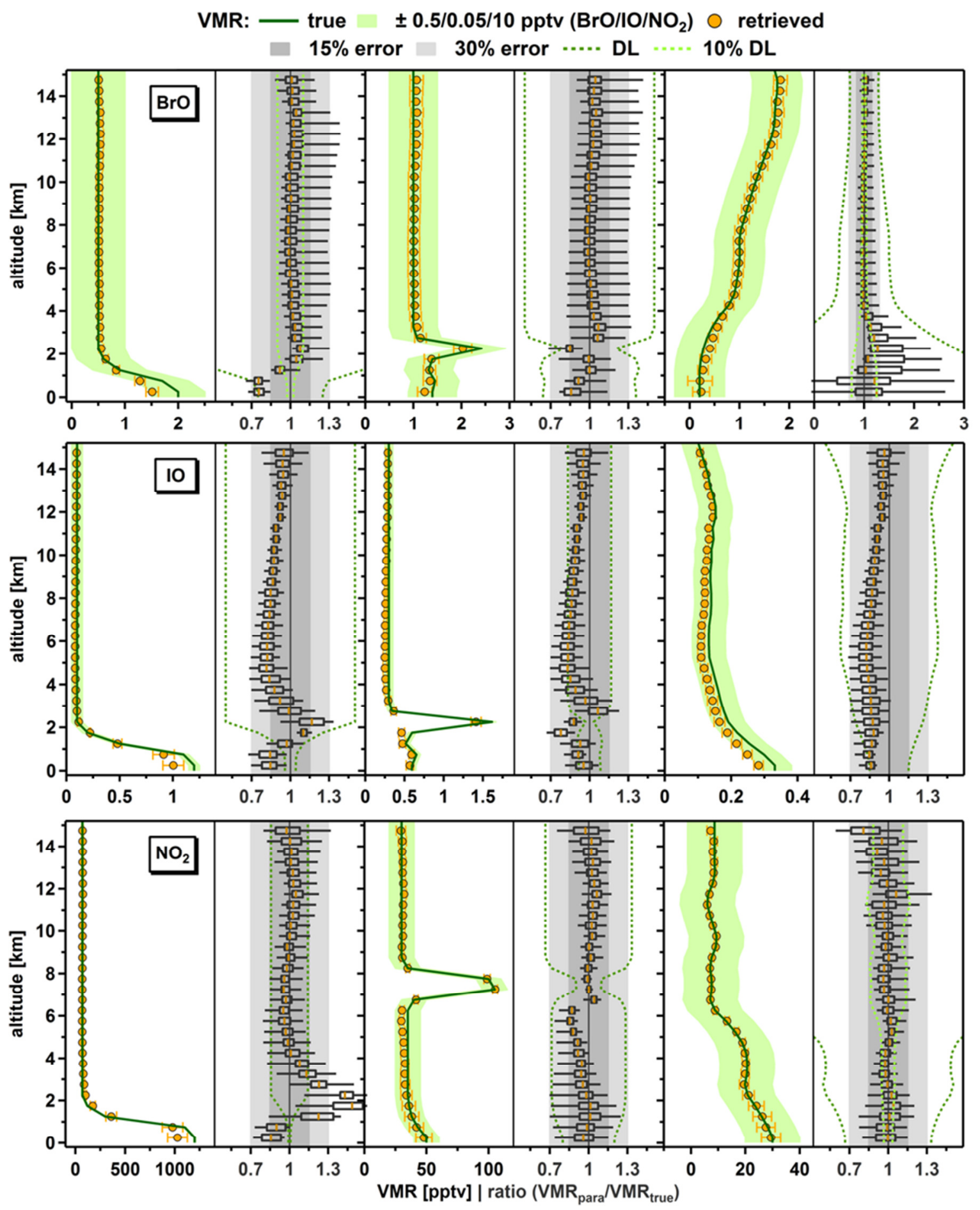

Figure S6. VMR $\mathrm{Vara}_{\text {for }} \mathrm{BrO}$ (top), IO (middle) and $\mathrm{NO}_{2}$ (bottom) a-, b-, and c- profiles (left to right), using dSCD data simulated for aerosol 2. Individual left panels show $\mathrm{VMR}_{\text {para }}$ average and standard deviation. Original trace gas profiles are included as reference and green shading denotes individual trace gas VMR error bounds. Right panels display altitude resolved whisker plots of the ratios of $\mathrm{VMR}_{\text {para }}$ over $\mathrm{VMR}_{\text {true }}$, showing the median (orange) and 5, 25, 75 and 95 percentiles. Grey shaded areas indicate $15 \%$ and $30 \%$ error; green dashed lines show trace gas detection limits. 

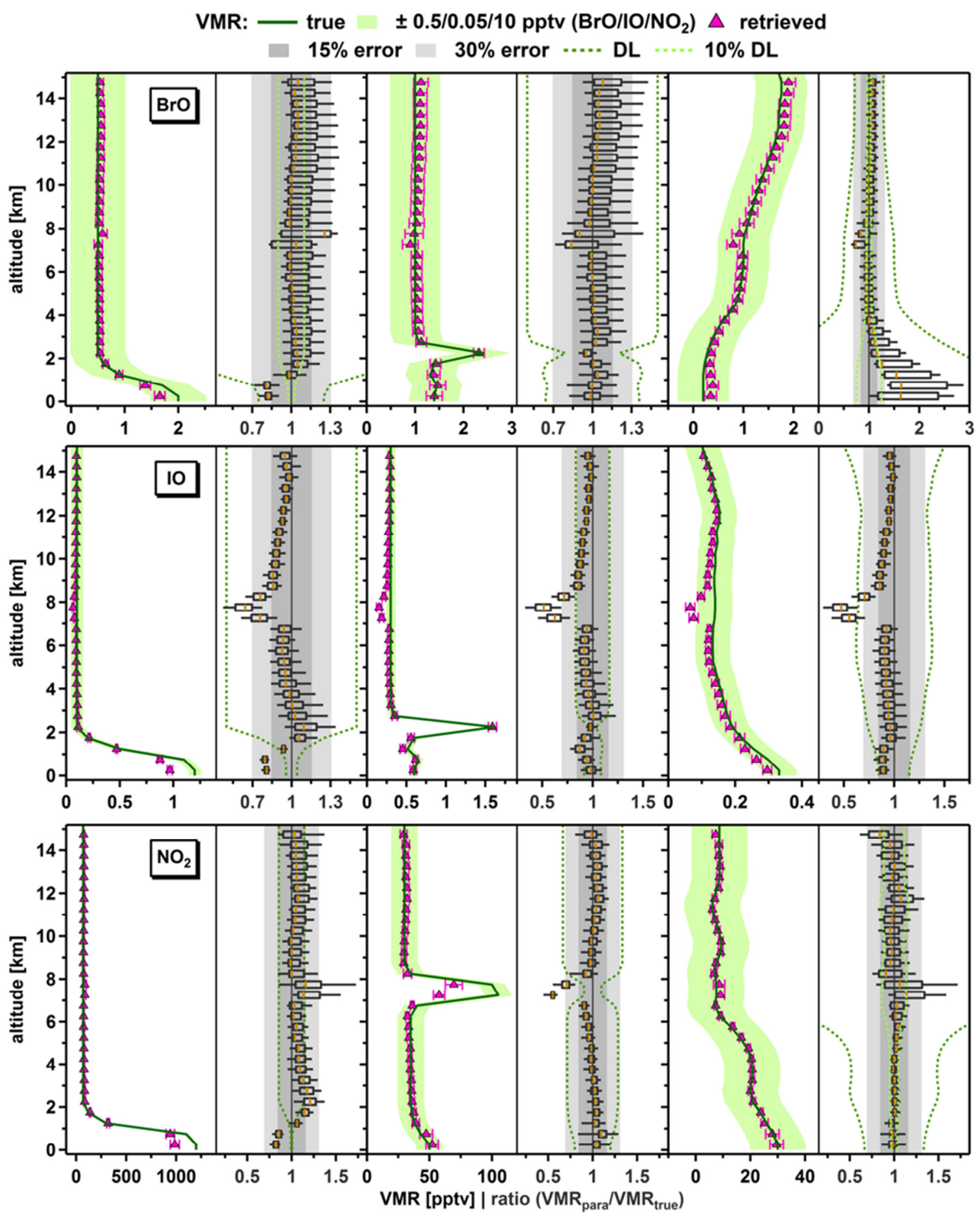

Figure S7. VMR $\mathrm{Vara}_{\text {for }} \mathrm{BrO}$ (top), IO (middle) and $\mathrm{NO}_{2}$ (bottom) a-, b-, and c- profiles (left to right), using dSCD data simulated for aerosol 3. Individual left panels show $\mathrm{VMR}_{\text {para }}$ average and standard deviation. Original trace gas profiles are included as reference and green shading denotes individual trace gas VMR error bounds. Right panels display altitude resolved whisker plots of the ratios of $\mathrm{VMR}_{\text {para }}$ over $\mathrm{VMR}_{\text {true }}$, showing the median (orange) and 5, 25, 75 and 95 percentiles. Grey shaded areas indicate $15 \%$ and $30 \%$ error; green dashed lines show trace gas detection limits. 


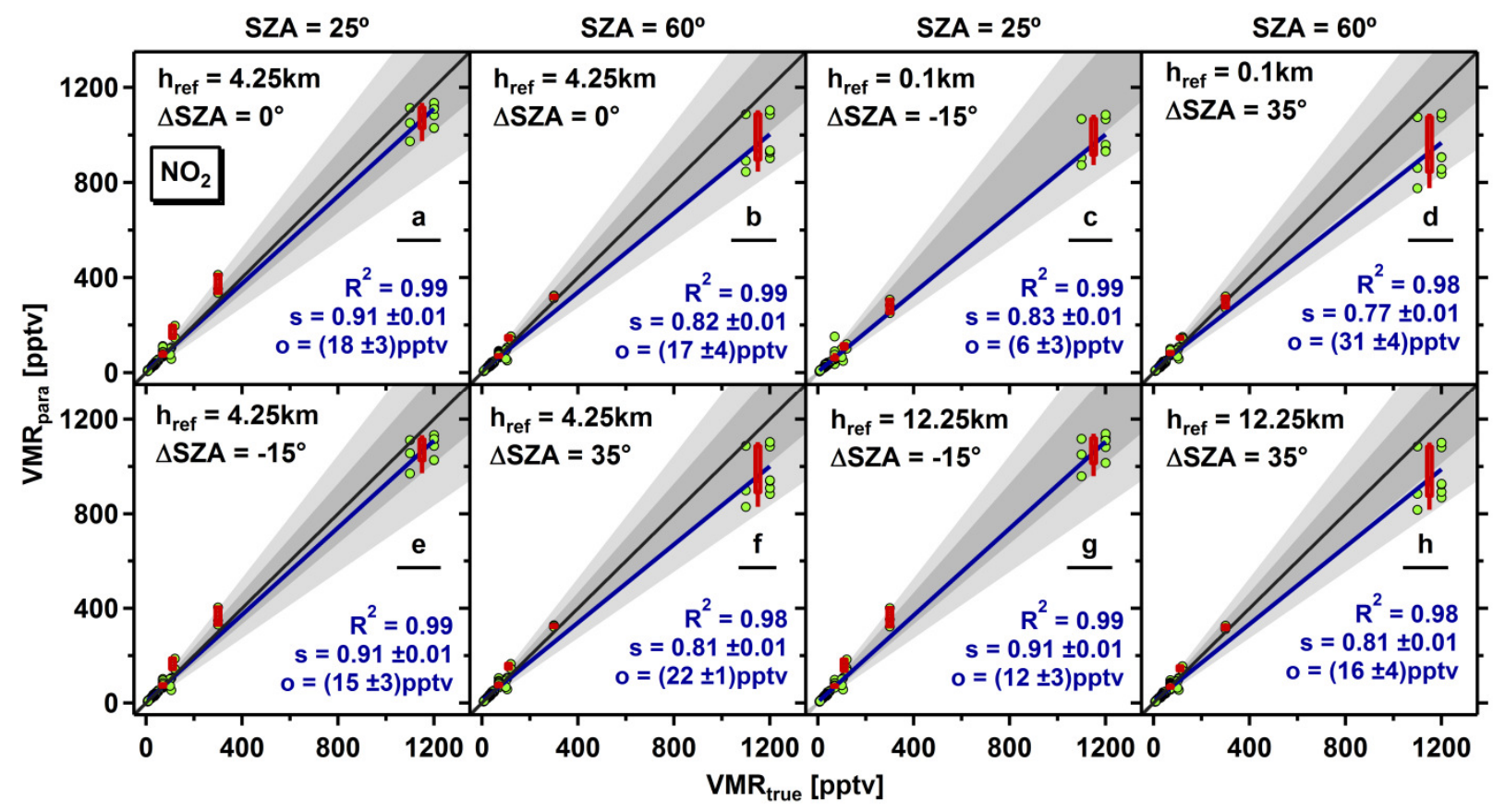

Figure S8. $\mathrm{VMR}_{\text {para }}$ over $\mathrm{VMR}_{\text {true }}$ for $\mathrm{NO}_{2}$ a- profile averaged over all aerosol profiles for select SZA, $\Delta \mathrm{SZA}$ and $h_{\text {ref. }}$ The panel columns alternate between low $\left(\mathrm{SZA}=25^{\circ}\right)$ and high SZA $\left(\mathrm{SZA}=60^{\circ}\right)$. Whisker plots show 5, 25, 75 and 95 percentiles for binned $\mathrm{VMR}_{\text {para }}$ data. Grey shaded areas indicate $15 \%$ and $30 \%$ error. Linear fits and fit parameter (s: slope, o: offset) are included in each panel. 

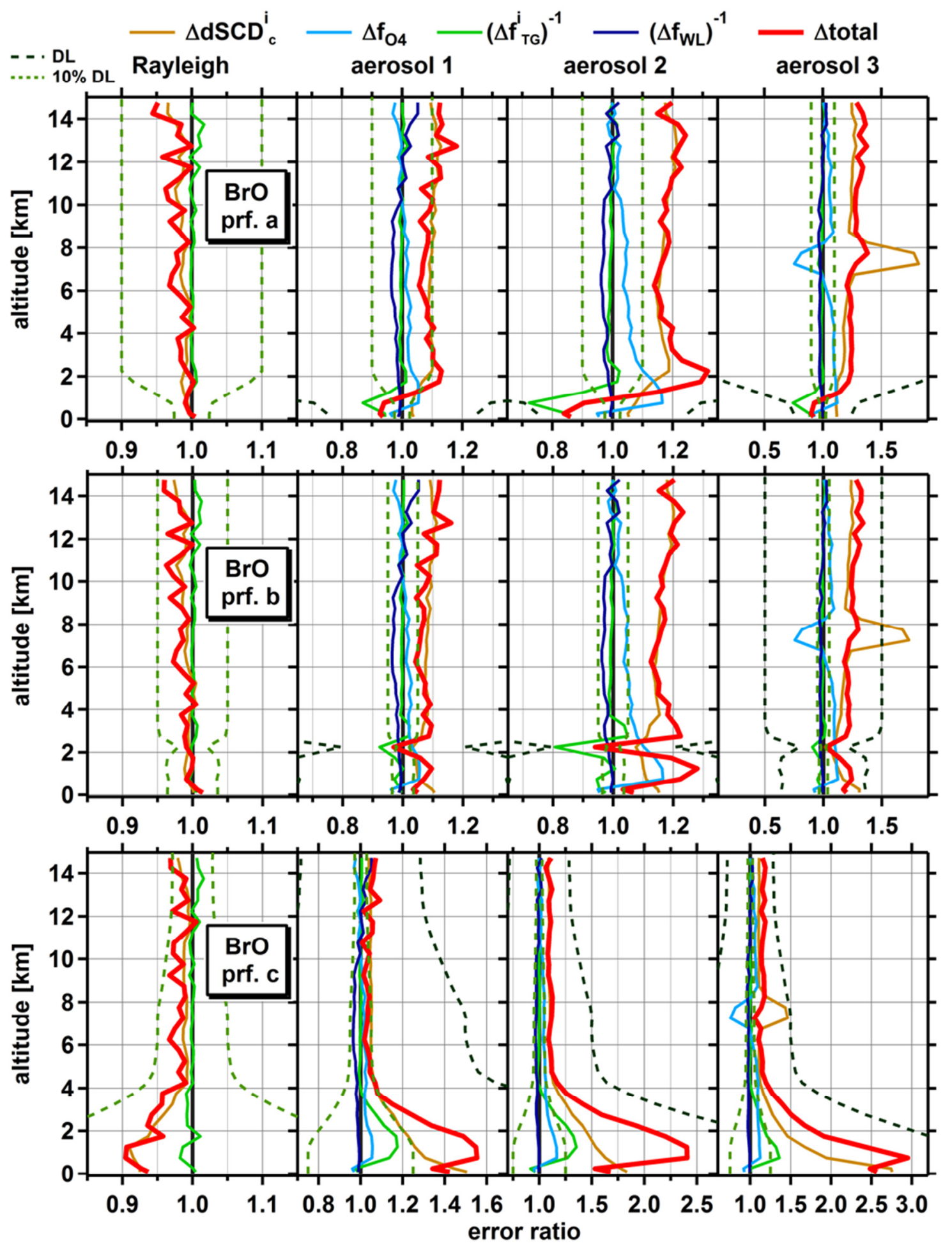

Figure S9. Total error and error ratios of individual components of Eq. (1) for all $\mathrm{BrO}$ profiles and atmospheres with $\mathrm{SZA}=25^{\circ}$ and $\triangle \mathrm{SZA}=25^{\circ}$. Reference altitude for $\mathrm{BrO}$ is $4.25 \mathrm{~km}$. Green dashed lines show trace gas detection limits. 

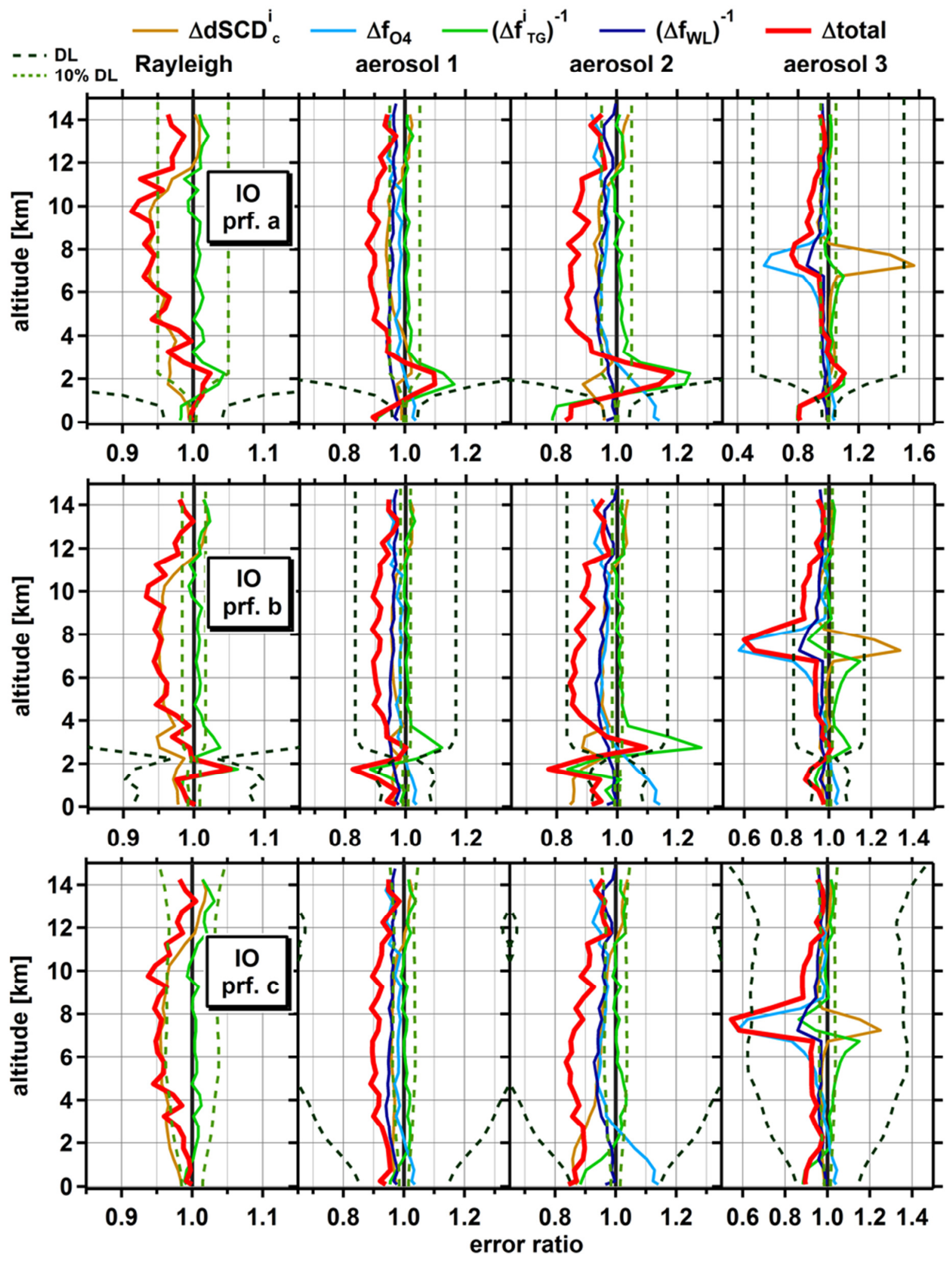

Figure S10. Total error and error ratios of individual components of Eq. (1) for all IO profiles and atmospheres with $\mathrm{SZA}=25^{\circ}$ and $\triangle \mathrm{SZA}=25^{\circ}$. Reference altitude for $\mathrm{IO}$ is $14.75 \mathrm{~km}$. Green dashed lines show trace gas detection limits. 

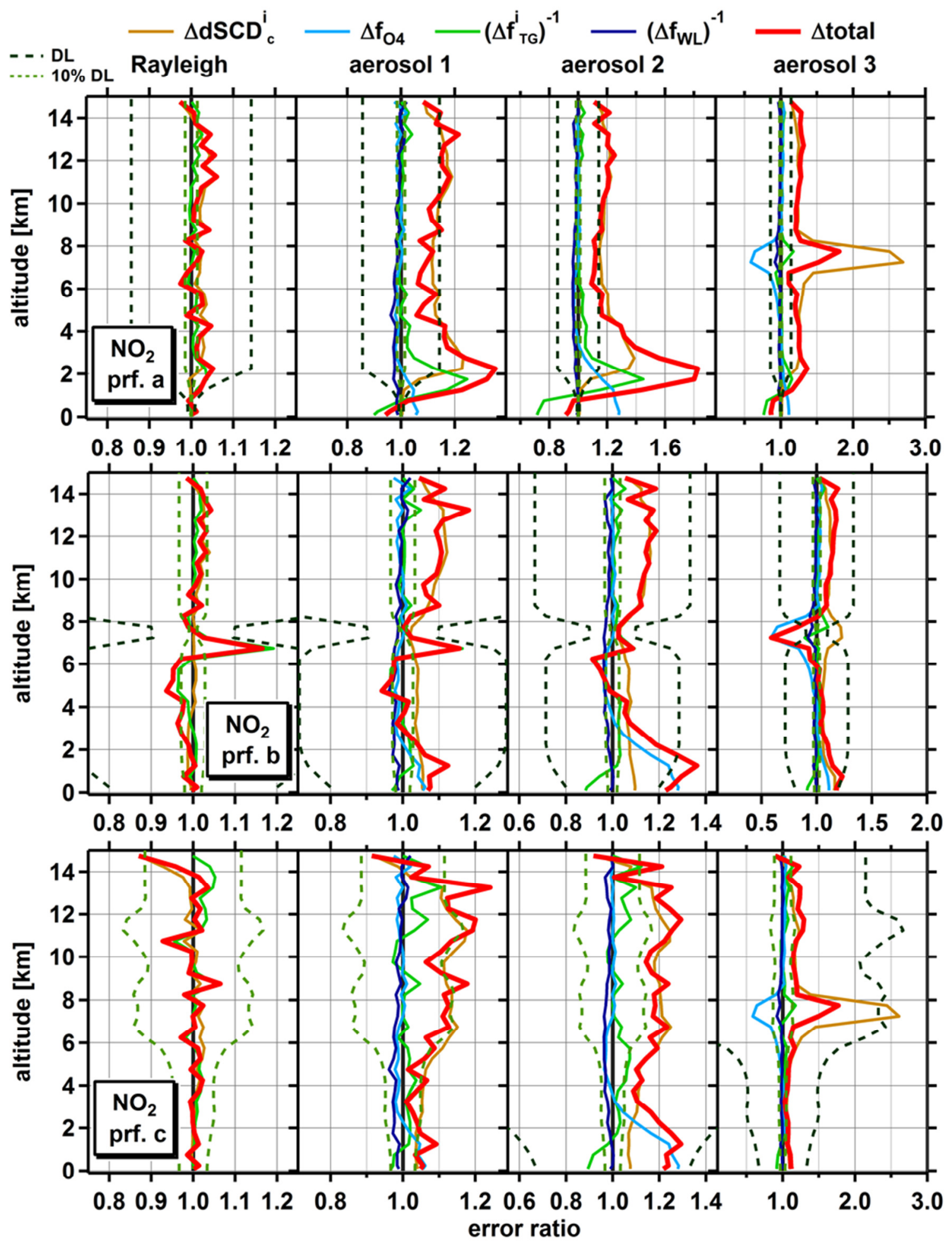

Figure S11. Total error and error ratios of individual components of Eq. (1) for all $\mathrm{NO}_{2}$ profiles and atmospheres with $\mathrm{SZA}=25^{\circ}$ and $\triangle \mathrm{SZA}=25^{\circ}$. Reference altitude for $\mathrm{NO}_{2}$ is $4.25 \mathrm{~km}$. Green dashed lines show trace gas detection limits. 


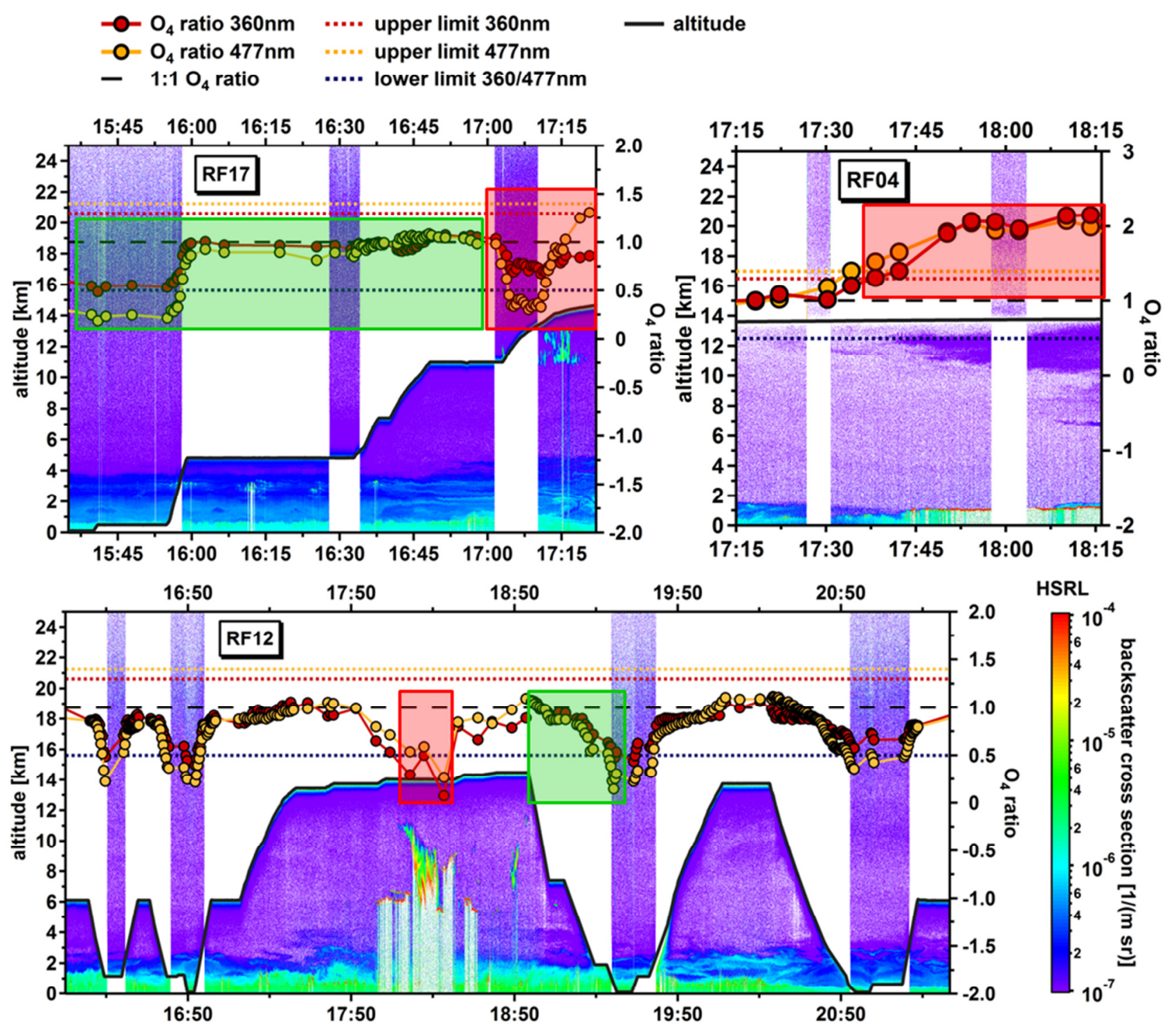

Figure S12. Comparison of $\mathrm{O}_{4}$ ratios at $360 \mathrm{~nm}$ and $477 \mathrm{~nm}$ with HSRL particulate backscatter cross section data for RF04, RF12 and RF17. Altitude resolved HSRL backscatter data is plotted and color coded along the flight track. Larger signals denote the presence of aerosol/clouds. HSRL is either measuring above or below the aircraft. The shading directly around the flight track seen in part of RF12 and RF17 is a near field effect that leads to erroneous large back scatter signals by HSRL. DOAS $\mathrm{O}_{4}$ ratios along the flight track are plotted on the right axis. Upper (red and orange dashed lines) and lower (blue dashed line) $\mathrm{O}_{4}$ ratio limits denote where aerosol/cloud conditions are considered too complex and respective trace gas dSCD data is not used for parameterization (Section 5.2). Note that the lower limit is only relevant when the aircraft is flying above cloud layers and does not apply to cloud free boundary layer legs. The one to one line is added as reference and signifies Rayleigh conditions. Red boxes show cases where dSCD data was filtered based on cloud conditions. Green boxes in RF12 and RF17 mark data periods that were used for BrO, IO and $\mathrm{NO}_{2} \mathrm{OE}$ profile 
retrievals as published in Volkamer et al. (2015). Regular HSRL upward scans show that for these time periods no aerosol or cloud layers were present above the aircraft.

The red box in RF17 displays an example where data is filtered because the aircraft is within $2 \mathrm{~km}$ of an elevated cloud layer. The cloud shields $\mathrm{O}_{4}$ concentrations below the cloud, which leads to very low measured $\mathrm{O}_{4}$ dSCDs and thus a very low $\mathrm{O}_{4}$ ratio. For the time period between 17:01 and 17:07 UTC, where HSRL scans upward, filtering is aided by aircraft video data. A similar effect is observed during RF12, marked by a red box. Here data is filtered based on exceeding the lower $\mathrm{O}_{4}$ ratio limit. The red box in RF04 shows an example where the aircraft flies across a rather solid low cloud layer situated at $\sim 1.2 \mathrm{~km}$ ( red HSRL backscatter data points), while almost simultaneously an optically thin aerosol layer right below the aircraft is encountered. The elevated aerosol layer is not sufficiently optically thick to shield $\mathrm{O}_{4}$ below. Instead, the increased albedo caused by both the boundary layer clouds and the lofted aerosol layer leads to measured $\mathrm{O}_{4}$ dSCDs that are up to a factor of two higher than those simulated for a Rayleigh case. Here, data points are filtered by the upper $\mathrm{O}_{4}$ ratio limits. 